\title{
REFLEXÕES SOBRE GUERRA HEGEMÔNICA CHINA E ESTADOS UNIDOS DA AMÉRICA
}

NA ATUALIDADE:

Alexandre Rocha Violante ${ }^{1}$ Etiene Villela Marroni ${ }^{2}$ André Valente $\mathrm{Maia}^{3}$

Resumo: $O$ objeto de estudo do artigo liga-se à hegemonia das potências no sistema internacional, haja vista as crescentes discussões por espaço e poder, visando um novo reequilíbrio sistêmico. Consequentemente, seu objetivo principal é analisar, sob o viés da Teoria da Guerra Hegemônica, os fenômenos no mundo atual, levando em consideração a história das guerras, as relações internacionais e os estudos estratégicos em sentido estrito. A pesquisa justifica-se, pois é possível que projetos de ganho de poder venham acarretar mudanças no status quo vigente, resultando em uma nova hegemonia, na manutenção da atual ou de um novo equilíbrio de poder, envolvendo, principalmente, os Estados Unidos da América como principal Hegemon - e a China - como principal potência revisionista -, o que não descarta o efetivo uso da força para o alcance de seus objetivos políticos. Por fim, conclui-se que a Teoria do Poder Hegemônico, seus conceitos e teorias derivadas contribuem para a sobrevivência do Estado, em um sistema internacional cada vez mais incerto.

Palavras-chave: Relações Internacionais. Hegemonia. Guerra Fria. China. Estados Unidos da América.

\section{REFLECTIONS ON HEGEMONIC WAR IN THE NOWADAYS: CHINA AND UNITED STATES OF AMERICA}

Abstract: The object of study of the article is linked to the hegemony of the powers in the international system, given the growing discussions for space and power aiming at a new systemic rebalancing. Consequently, its main objective is to analyze, under the Hegemonic War Theory, the phenomena in the present, taking into account the history of wars, international relations and strategic studies in the strict sense. The research is justified because projects of power gain may lead to changes in the current status quo, resulting in a new hegemony, the maintenance of the current or a new balance of power, involving mainly the United States - as the main Hegemon - and China - as the main revisionist power - which does not rule out the effective use of force to achieve its political goals. Finally, it is concluded the Hegemonic Power Theory, its concepts and theories derived contribute to the survival of the state in an international system increasingly uncertain.

Keywords: International Relations. Hegemony. Cold War. China. United States of America.

\section{REFLEXIONES SOBRE LA GUERRA HEGEMÓNICA EN LA ACTUALIDAD: CHINA Y ESTADOS UNIDOS DE AMÉRICA}

1 Universidade Federal Fluminense, Programa de Pós-Graduação em Estudos Estratégicos da Defesa e da Segurança (PPGEST), Rio de Janeiro, Brasil, alexandreviolante@id.uff.br, http://orcid.org/0000-0003-4566-5252

2 Universidade Federal de Pelotas, Programa de Pós-Graduação em Ciência Política (PPGCPol), Pelotas, Brasil, etiene.marroni@ufpel.edu.br, http://orcid.org/0000-0001-8067-5865

3 Universidade Federal do Rio Grande do Sul, Programa de Pós-Graduação em Estudos Estratégicos Internacionais (PPGEEI), Porto Alegre, Brasil, andrevmaia@gmail.com, https://orcid.org/0000-0001$7062-2524$ 
Resumen: El objeto de estudio del artículo está vinculado a la hegemonía de los poderes en el sistema internacional, dadas las crecientes discusiones por el espacio y el poder que apuntan a un nuevo reequilibrio sistémico. En consecuencia, su principal objetivo es analizar, bajo la Teoría de la Guerra Hegemónica, los fenómenos del presente, teniendo en cuenta la historia de las guerras, las relaciones internacionales y los estudios estratégicos en sentido estricto. La investigación se justifica porque los proyectos de ganancia de poder pueden conducir a cambios en el status quo actual, resultando en una nueva hegemonía, el mantenimiento de la actual o un nuevo equilibrio de poder, involucrando principalmente a Estados Unidos -como principal Hegemón- y China - como principal potencia revisionista - lo que no descarta el uso efectivo de la fuerza para lograr sus objetivos políticos. Finalmente, se concluye la Teoría del Poder Hegemónico, sus conceptos y teorías derivadas contribuyen a la supervivencia del Estado en un sistema internacional cada vez más incierto.

Palabras clave: Relaciones Internacionales. Hegemonía. Guerra Fría China. Estados Unidos de América.

\section{Introdução}

A guerra hegemônica é diferente de outras guerras, pois remodela o Sistema Internacional, promovendo mudanças na hierarquia de poder entre os Estados. Sua causa principal é sempre implícita - a desconformidade da ordenação maior entre os Estados, seja de origem política, econômica, estratégica, ideológica e estrutural. Seus resultados são imprevisíveis, podendo, inclusive, um terceiro Estado tirar grande proveito do embate entre os dois contendores. Foi o que ocorreu no PósGuerra do Peloponeso com a Macedônia, no Pós 1a Guerra Mundial com os EUA e ao longo da Guerra Fria, com a China, que angariou poder no Sistema Internacional por meio de entendimentos pragmáticos em diversas áreas de cooperação com os EUA.

De fato, as grandes transformações na história mundial derivaram-se de guerras hegemônicas entre rivais políticos, cujo resultado foi o reordenamento do Sistema Internacional a partir de ideias e valores do Estado vencedor. Uma guerra hegemônica caracteriza-se por: "contestação direta entre poder dominante e Estados revisionistas, mudanças na natureza e na governança do sistema e meios de violência quase ilimitados" (GILPIN, 1981;1987).

Não há vácuo de poder. Isso ocorreu no Pós-Guerra Fria pela perda de influência da Rússia sobre muitos países do Sudeste Asiático, do Japão, como polo agregador do desenvolvimento da Ásia Oriental, e dos EUA, ao concentrarem maior parte de seus esforços militares no Oriente Médio (PAUTASSO, 2011).

A China tem buscado reafirmar-se como grande centro capaz de assumir a liderança, tanto dos mecanismos formais quanto dos informais, da integração 
regional do leste da Ásia, como ocorreu ao longo dos períodos dinásticos. A retórica oficial dos líderes do Partido Comunista Chinês, em certo aspecto, é pautada por ideias-força voltadas ${ }^{4}$ ao desenvolvimento nacional. A partir de 2003, a noção de ascensão pacífica foi a primeira manifestação oficial do desejo de maior projeção internacional. A partir da crise de 2008 e sob a liderança de Xi Jinping, a China passou a adotar estratégias e abordagens de caráter mais afirmativo, como na tentativa de reformular normas e instituições do cenário global, para que estas reflitam, também, os valores e prioridades chineses. Isso vai ao encontro das recentes iniciativas de fortalecimento do soft power e de seu hard power, em uma estratégia notadamente voltada à formatação de uma nova arquitetura financeira global e à construção da Nova Rota da Seda - o OneBelt, OneRoad (OBOR) (PAUTASSO, 2015).

Tal redirecionamento político e econômico do Estado chinês absorve conceitos do imperialismo ao qual, em sentido positivo, era entendido por Dante Alighieri, em seu livro De Monarchia, como sinônimo de paz mundial, como ordenamento de um sistema que evitasse as guerras. Contudo, passou a ser interpretado negativamente, como uma contradição ao princípio da autodeterminação dos povos. Como exemplo, temos a imposição de um imperialismo agressivo em 1870, na Inglaterra Vitoriana, e no período entre 1914 a 1945, no Japão e sociedades europeias (PISTONE, 2008). Nesse aspecto, o autor ressalta que existe uma "expansão violenta por parte dos Estados, ou de sistemas políticos análogos, da área territorial de sua influência, ou poder direto, e formas de exploração econômica em prejuízo dos Estados ou povos subjugados".

Assim, hegemonia possui uso diferente do imperialismo. Estado hegemônico, segundo Belligni (2008), refere-se a uma potência que exerce sobre os outros Estados uma preeminência não apenas militar, mas econômica e cultural, condicionando-Ihes as opções a serem seguidas, em face de seu elevado potencial intimidatório e coercitivo. Keohane (1984, p.34) reitera que o Estado hegemônico "é suficientemente poderoso para ser capaz de manter as regras essenciais que governam as relações entre Estados e que tem a determinação para assim mantêlas".

\footnotetext{
${ }^{4}$ De acordo com Magendzo (2009, p.5), este conceito se refere a ideias e pensamentos convergentes e complexos, com grande capacidade de mobilização, estando "enraizados" historicamente "[...] como criação, como produção de diferenças e diversidades, como transformação, como movimento, em definitiva, como um processo".
} 
O estudo, portanto, possui como objetivo principal verificar, sob o viés da Teoria da Guerra Hegemônica, os fenômenos no mundo atual que envolvem os EUA e a China, levando em consideração a História das Guerras, as Relações Internacionais e os Estudos Estratégicos em sentido estrito ${ }^{5}$. Como método, nesse estudo, destaca-se a análise de conteúdo que, segundo Bardin (2011) leva a obtenção, por procedimentos sistemáticos e objetivos, de descrição de conteúdos relativos aos referencias analisados. Para tanto, serão revisados conceitos de imperialismo, hegemonia e soberania, além de Teorias Internacionalistas derivadas da Teoria do Poder Hegemônico. São apresentadas essas relações do poder hegemônico com as guerras hegemônicas na contemporaneidade, ou seja: até a Guerra Fria e no Pós-Guerra Fria, além de breves comentários sobre o porvir entre EUA e China.

\section{Imperialismo, Hegemonia e Soberania na Contemporaneidade: Revisitando Conceitos}

O imperialismo, após 1945, passou a desenvolver-se nas relações hegemônicas entre as duas superpotências (EUA e ex-URSS), em uma nova política neocolonialista de viés econômico por parte dos EUA e, em menor escala, pelas demais potências centrais (PISTONE, 2008).

Há tipos de hegemonia que devem ser citados. Pode-se classificar de hegemonia unilateral ou coercitiva aquela que supõe o desenvolvimento de normas ou de um sistema de relações feito entre Estados pelo uso da força, por meio da coerção ou da coação, podendo incluir a utilização de força militar direta. Existe, ainda, a hegemonia cooperativa ou benevolente. Tal tipo seria uma forma equilibrada de aplicação de poder, que buscaria a legitimidade e a estabilidade, estruturalmente (HASENCLEVER; MAYER e RITTBERGER, 1997; LUDWIG, 2013).

Observa-se, também, a concepção marxista de hegemonia cultural, desenvolvida por Gramsci (2000, p.248), ao constatar que "o exercício usual da hegemonia [...] é caracterizado pela combinação de força e consentimento. [...] A tentativa é sempre fazer com que a força pareça ser baseada no consentimento da maioria, expressa pelos chamados órgãos de opinião pública". O desenvolvimento do conceito gramsciano de hegemonia significa a aplicação de uma ordem política

\footnotetext{
${ }^{5}$ Entendem-se os Estudos Estratégicos, em sentido estrito, como a aplicação ou a capacidade crível de uso da força, do poder contra um oponente, (inclusive da força militar) por meio do uso da estratégia, para atingir seus fins, que são os objetivos políticos de uma unidade política (no caso em Estudo, do Estado).
} 
relativamente incontestada e aceita passivamente, em uma combinação da coerção e de consentimento, o que abre um leque de múltiplas possibilidades de reinterpretação da realidade internacional (SILVA, 2005). Com isso, os valores morais, políticos e culturais do grupo dominante são dissipados por meio das instituições da sociedade, por meio de significados compartilhados e noções de consentimento, sem que haja contestações ou potências emergentes revisionistas do status quo vigente.

Sobre os tipos de hegemonia, os Estados podem exercer, simultaneamente, seus diversos tipos, combinando-os de acordo com suas estratégias. Percebe-se que a hegemonia unilateral se destaca pela possibilidade ou uso da força, enquanto as hegemonias cooperativas e culturais estão mais ligadas ao cognitivismo.

Sobre a soberania, conceito inter-relacionado diretamente à hegemonia, Bodin (1992) a estabeleceu no século XVII como um poder indivisível, inalienável, absoluto e perpétuo, o que torna o Estado moderno sujeito único e exclusivo da política. Em uma visão mais ampla de Weber (1996), o Estado moderno teria, na centralização do poder adquirido, o seu próprio caráter, em nível histórico e institucional, com o monopólio da força legítima.

No decorrer do século XX, o conceito político-jurídico de soberania entrou em crise. O Estado moderno era incapaz de se apresentar como único e autônomo centro de poder exclusivo da política internacional. A partir do final da $2^{\mathrm{a}}$ Guerra Mundial e, principalmente, no Pós-Guerra Fria, sua relativização ganhou força, por meio de ideias que buscavam subordinar o Estado a comunidades supranacionais, como cortes internacionais de justiça, comunidades econômicas, novas alianças militares e arranjos de segurança coletiva (MATTEUCCI, 2008). O Estado não desapareceu, mas tem se modificado como forma de organização do poder.

O conceito de soberania jamais foi unânime quanto à sua significação, validade prática ou viabilidade política, estando sujeito a desconstruções motivadas por interesses altruístas e/ou concomitantemente ligados aos Estados hegemônicos. Um desses esforços relaciona-se à limitação de tarefas das forças armadas de Estados em desenvolvimento ou de potências emergentes. Para os Estados com maior poder relativo sistêmico, essas relativizações têm, como principal argumento, a ineficiência dos chamados Estados falidos ou frágeis ${ }^{6} \mathrm{em}$ manter a sua própria

\footnotetext{
${ }^{6}$ Estado falido é visto pela comunidade internacional como aquele incapaz de governar, de forma adequada, seu território e população, representando um risco para o bem-estar e a segurança interna e internacional. Estado frágil pode ser conceituado como um degrau abaixo ao Estado falido, ou seja, aquele que possui dificuldades em se estabelecer institucionalmente.
} 
segurança, de seus cidadãos e, por conseguinte, a segurança internacional (FIGUEIREDO, 2015). Tal conceito desenvolveu-se de forma tipicamente ocidental, representando uma limitação questionável, política e conceitual, estando ligado ao ressurgimento das "novas ameaças" no cenário internacional.

\section{As Guerras Hegemônicas na Contemporaneidade (até a Guerra Fria)}

"A História da Guerra do Peloponeso" (431 a.C. a 404 a.C.), de Tucídides descreve os detalhes da guerra entre as Cidades-Estado, Esparta e Atenas. Cidades-Estado era a forma de organização política e social da época, em que Atenas exercia a "democracia", enquanto Esparta desenvolvia um sistema próximo a uma "oligarquia despótica". Atenas possuía expertise militar nas lides do mar, enquanto Esparta desempenhava-se muito bem na guerra terrestre. Os relatos de Tucídides fomentaram o estabelecimento de Teoria do Poder Hegemônico, sendo um dos maiores contributos às Relações Internacionais.

Como antecedentes dessa Guerra, é interessante pontuar que, durante as guerras de expansão do Império Persa, Esparta, potência terrestre e agrícola, detentora de dois quintos do Peloponeso, não possuía interesses externos aos seus domínios, enquanto Atenas, potência marítima, comercial e cultural, almejava grandes interesses internacionais. Tais Cidades-Estado possuíam interesses complementares e não excludentes. Portanto, em um primeiro momento, não possuíam motivos para se antagonizarem, fortalecendo-se, reciprocamente, por meio de uma aliança (JAGUARIBE, 2001).

Logo, conforme as observações de Tucídides, os Estados comportavam-se de acordo com o crescimento diferencial de poder entre eles, identificando a hegemonia como projeto de poder nacional. Os conceitos, até aqui discutidos, podem ser entendidos como derivados da Teoria do Poder Hegemônico. Tal teoria esclarece que a estabilidade sistêmica depende da distribuição de poder, ou seja, se o ator hegemônico é satisfeito, o sistema é estável, caso contrário torna-se instável, devido a demandas de outros atores que ameaçam seu poder.

\footnotetext{
7 São comumente identificadas como: terrorismo, tráfico ilegal de armas, drogas e pessoas, pesca ilegal, contrabando, descaminho, pirataria e até ações terroristas.

8 Tucídides foi considerado o primeiro historiador moderno. Ele procurou relatar, objetivamente, os fatos como haviam ocorrido na Guerra do Peloponeso. Sua preocupação com as fontes primárias, os discursos e a prática dos combates - que acompanhou diretamente ou bem de perto -, demonstra o cuidadoso levantamento de dados efetuado, solidificando a sólida metodologia de pesquisa de sua obra (JAGUARIBE, 2001).
} 
Allison (2017), em estudos sobre a Guerra Hegemônica, promoveu a criação de um conceito ligado aos ensinamentos da Guerra do Peloponeso, que se denomina "Armadilha de Tucídides", em que a natureza humana (o medo, o orgulho e o interesse) torna a guerra inevitável. Assim, na medida em que uma potência se desenvolve cresce a demanda por respeito, para que esse poder ascendente seja reconhecido no Sistema Internacional estabelecido.

Além da Guerra do Peloponeso, a Guerra dos 30 anos (1618-48), as guerras revolucionárias e napoleônicas (1792-1815) e as 1aㅡ e $2^{\underline{a}}$ Guerras Mundiais (1914-18; 1939-45) foram conflitos hegemônicos que buscaram modificar o sistema, inseridos na perspectiva clausewitziana de que foram conflitos ilimitados, aproximando-se do conceito de guerra absoluta do estrategista prussiano. (GILPIN, 1989).

Como exemplos das análises de Gilpin e Allison, a Paz de Vestfália (1648), uma série de Tratados que pôs fim à Guerra dos $80 \operatorname{anos}^{9}$ e à Guerra dos $30 \operatorname{Anos}^{10}$, consolidou o conceito de Estado Nacional, inaugurando o princípio da soberania estatal e a abertura de novos mercados consumidores. Tal contexto envolvia as grandes navegações e o colonialismo. O Sistema Vestfaliano redefiniu as fronteiras políticas da Europa, alterou o equilíbrio do poder e criou uma disputa pela hegemonia mundial, culminando com as guerras napoleônicas e, a posteriori, nas $1^{\text {a }}$ e $2^{\text {a }}$ Guerras Mundiais (LESSA, 2005).

Entretanto, foi nas discussões do Congresso de Viena (1815) que se instituiu o concerto das Nações e se estabeleceu um equilíbrio entre as principais potências - a chamada Pax Britannica ${ }^{11}$ - por meio de diretrizes que propiciaram alguma estabilidade e uma gestão com certo compartilhamento de poder até $1^{\underline{a}}$ Guerra Mundial (KENNEDY, 1989).

A conjuntura política da Europa, antes da "Grande Guerra", assemelhava-se àquela da "Paz de 30 Anos" na Grécia antiga. Um sistema internacional regido por equilíbrio de forças, em que nenhum dos dois blocos antagônicos, liderados pelo Reino Unido e pela Alemanha, podia, sem graves riscos, permitir o unilateral fortalecimento do outro (JAGUARIBE, 2001).

\footnotetext{
${ }^{9}$ A Guerra dos 80 anos ou Revolta Holandesa de 1568 a 1648 foi a Guerra de Secessão, em que o território que hoje engloba os Países Baixos se tornou um país independente frente à Espanha.

10 A Guerra dos 30 Anos (1618-1648) representou uma série de guerras que envolveram várias Nações europeias a partir de 1618, especialmente na Alemanha. Os motivos que levaram aos conflitos foram: religião, dinastias, território e comércio.

11 Pax Britannica é empregado de forma análoga ao termo Pax Romana. Retratou o extenso período de relativa paz na Europa desde o fim da Batalha de Trafalgar (1805) até o início da 1a GM, em que o Império Britânico obteve sua maior extensão colonial, atingiu sua supremacia industrial e angariou posições privilegiadas por meio de sua poderosa marinha.
} 
A proposta de criação de um sistema de segurança coletivo representava uma ruptura com o equilíbrio de poder, que havia regido as relações entre as potências europeias antes do final da $1^{\text {a }}$ Guerra Mundial. A balança de poder permitia a manutenção da ordem internacional, na medida em que o sistema de alianças impedia que um dos Estados ameaçasse a soberania dos demais. $\mathrm{O}$ novo sistema buscou criar mecanismos que valorizassem a solução pacífica de conflitos em caso de crise, por meio da dedicação da Liga à investigação, ao desarmamento, à mediação e à arbitragem (RIGGS e PLANO, 1994).

As duas principais correntes das relações internacionais da época explicam o fracasso desse novo arranjo de Estados. Para os ditos realistas clássicos, a Liga fracassou porque não era arregimentada no poder e as organizações internacionais não eram as principais mantenedoras da ordem em um sistema anárquico, mas sim as grandes potências (CARR, 1981; WALTZ, 2002). Para os teóricos idealistas/liberais, sua derrocada derivou do enraizamento, ainda existente, do equilíbrio de poder europeu, tendente à guerra.

A existência da Liga não evitou diversos conflitos e a corrida armamentista, que precederam a 2 ${ }^{\mathrm{a}}$ Guerra Mundial. Entre muitos fatores, seu fracasso ocorreu pela tensão entre o conceito de soberania e a lógica da indivisibilidade da paz, pela ausência dos EUA no concerto e pelo caráter extremamente punitivo do tratado de Versalhes, que declarava a Alemanha como única responsável pela deflagração da guerra, gerando um sentimento revanchista e de fortes paixões, como ocorrera na guerra hegemônica anterior.

A inoperância desse mecanismo de segurança resultou na $2^{\mathrm{a}}$ Guerra Mundial. A Alemanha, insatisfeita política, econômica e ideologicamente com o Sistema Internacional que vigia, buscava, novamente, uma posição hegemônica prioritária em toda Europa e em outras partes do globo. A Alemanha enfrentou contendores que detinham o poder sistêmico, o qual buscava revolucionar, principalmente a França e o Reino Unido ${ }^{12}$. A possibilidade de ter suas áreas de influência ameaçadas, como o Continente Americano e o Pacífico, motivou a entrada dos EUA na Guerra, principalmente após o ataque do Japão a Pearl Harbor. Tal fato, concomitantemente à expulsão da Alemanha do front oriental pela ex-URSS, alterou, sensivelmente, o equilíbrio que se apresentava.

${ }^{12}$ Convém lembrar que, por não ser capitalista, a ex-URSS estava alijada do Sistema Internacional da época. 
Posteriormente a esse outro conflito hegemônico, surgiu um novo sistema de segurança coletiva, - a Organização das Nações Unidas (ONU) - que persiste até hoje. Tentando evitar os erros do passado, foi criado um processo decisório em que as grandes potências passaram a ter uma "soberania especial", na forma de poder de veto, com as principais decisões sobre segurança tomadas por este seleto grupo. Criava-se, então, o Conselho de Segurança das Nações Unidas ${ }^{13}$ (CSNU). Praticamente, esse sistema de segurança não funcionou durante a Guerra Fria (1947-1991), entretanto a bipolaridade hegemônica dos blocos capitalista e socialista manteve o sistema estabilizado em guerras regionalizadas, onde a hegemonia única não foi alcançada, muito devido à deterrência da Mutual Assured Destruction (MAD) da era nuclear, em que a racionalidade venceu as paixões (HERZ e HOFFMANN, 2004).

\section{O Poder Hegemônico no Pós-Guerra Fria - As Novas Potências Emergentes}

A última década do século XX, fruto da queda do Muro de Berlim em 1989 e do colapso da ex-União das Repúblicas Socialistas Soviéticas (ex-URSS) em 1991, primou pela rapidez de análises conclusivas sobre o futuro das Relações Internacionais. As características da Guerra Fria, que envolviam, na bipolaridade, o uso de armamentos nucleares em sua corrida armamentista, deixaram de desempenhar um papel extremamente relevante no modo de se definir a segurança. A ênfase no Estado, ao estudo da ameaça, do uso e do controle da força militar para a resolução de controvérsias, deixou de ser preponderante, mas não menos importante. Assim, o campo teórico dos estudos estratégicos sofreu modificações consideráveis (WALTZ, 2002).

Uma das características do Pós-Guerra Fria é a ausência de um processo amplo de reconstrução da ordem internacional, em contraponto a outros momentos em que as potencias buscaram redefinir parâmetros e instituições, como na assinatura do Tratado de Vestfália (1648), Utrecht (1713), Congresso de Viena (1815) e Versalhes (1919). Novos temas ascenderam à agenda de segurança das grandes potências. De acordo com Buzan e Hansen (2012, p.37), a ampliação do conceito de segurança reflete preocupações crescentes com temas além daqueles presentes na "agenda político-militar e na epistemologia positivista tradicional", com enfoque de segurança que atenda novas demandas, diferentes das ameaças

13 O CSNU é formado por cinco membros permanentes e dez temporários. Os cinco membros permanentes que possuem poder de veto em suas resoluções são: EUA, Rússia, China, França e Reino Unido. 
tradicionais (soberania e território), com a securitização ${ }^{14}$ de qualquer outro tema que possa colocar em risco indivíduos, sociedades e o próprio Estado, afetando diretamente suas soberanias.

O poder continuou a representar o principal elemento do Sistema Internacional, mas a moral incrementou-se. Não que, no entre guerras, a Alemanha não fundamentasse suas invasões em princípios éticos, mas, a partir do final da $2^{\underline{a}}$ Guerra Mundial e, principalmente, no Pós-Guerra Fria, cada vez mais o Hegemon fundamentou seus interesses sob preceitos éticos, de liberdade e democracia. Tais argumentos foram criados para justificar a manutenção do status quo, ou para alterá-lo a favor do(s) hegemon(s). Carr (1981, p.139) ressaltava que, "no âmbito internacional, as teorias da moral internacional são produto das Nações ou grupos de Nações dominantes, um artifício moral engenhoso, invocado para justificar e manter sua posição dominante".

Houve, portanto, a necessidade de repensar novos atores e novos temas à high politics. Surgiram ou foram apresentados outros conceitos e teorias, que adquiriram fundamentos mais estruturalistas. O próprio realismo e liberalismo adequaram-se a essa nova realidade. O institucional-liberalismo de Nye (2012) afirma que a manutenção da hegemonia depende do exercício habilidoso de um complexo conjunto de recursos e relações comportamentais de poder. Para ele, ocorrem, na contemporaneidade, fenômenos de difusão e transferência de poder em escala global, o que impede que os recursos de hard Power (aplicação do poder econômico e militar) sejam suficientes, isoladamente, para garantir a dominação dos Estados hegemônicos. A combinação desses recursos hard com os instrumentos de soft power formariam uma estratégia smart ${ }^{15}$, mais eficiente para tal objetivo político. É uma teoria aplicada a Estados não revisionistas, que buscam maior poder relativo pelo bandwagoning e, obviamente, à manutenção de poder do atual Hegemon - os EUA.

No entanto, alguns aspectos da Política Internacional não mudaram desde a Guerra do Peloponeso. O dilema da segurança - que se refere a uma situação na qual dois ou mais Estados são levados a uma situação de insegurança, pois não é possível medir claramente seus poderios militares, direcionando-os ao conflito continua atual. Com isso, o medo continua como maior estimulante ante a incerteza

\footnotetext{
${ }^{14}$ Práticas intersubjetivas em que um agente identifica a existência de ameaças à sobrevivência de um objeto (BUZAN et al., 1998).

${ }^{15}$ É a estratégia que combine o hard power - poder econômico e poder militar - com o soft power das demais facetas do poder, que englobam a persuasão e da atração.
} 
entre Estados revisionistas e hegemônicos, em seus níveis de influência regional e global, acarretando no desenvolvimento de formas de proteção por parte do Estado, por meio de investimentos em armamentos.

Nesta linha de pensamento, outras teorias internacionalistas foram alteradas. Waltz (2002) e Mearsheimer (2007) modificaram o Realismo a partir dos anos 1970 e 1980, ao introduziram o elemento estrutural à análise teórica, de modo que não era mais a natureza humana a única razão do comportamento dos Estados - uma das suposições da Teoria da Guerra Hegemônica. Os fatores exógenos e as características do nível sistêmico passaram a ser variáveis independentes para tais teorias. Assim, opta-se pela racionalidade, na tentativa de se combater as paixões, evitando atitudes baseadas no ímpeto da conquista. Logo, os cálculos de ataque devem ser bem feitos, priorizando a prudência, a fim de não se cair na "armadilha de Tucídides".

Esse realismo dividiu-se em defensivo e ofensivo. O realismo defensivo de Waltz tem, como principal objetivo, equilibrar o sistema internacional, evitando conflitos e o surgimento de novas hegemonias. Para tal, a guerra seria a última ratio, quando esgotadas todas as formas de cooperação e acordos possíveis. Sendo assim, busca-se maximizar a segurança com a obtenção de tanto poder quanto for necessário, para manter sua posição no sistema e nada mais. Os defensores dessa corrente são mais conservadores do que expansionistas e visam à manutenção do status quo. De forma mais incisiva, o realismo ofensivo visa à aquisição do maior poder possível, de modo a incrementar a posição internacional do Estado hegemônico no sistema. Com isso, evita-se que as potências emergentes alcancem a posição de hegemons globais ou regionais.

\section{Hegemonia dos EUA versus Revisionismo da China}

Ao longo deste século, pode-se dizer que a estratégia de inserção internacional dos EUA se baseou mais no hard power do que na combinação do hard com o soft power. Durante o governo de George W. Bush (2001-2009), os EUA enfatizaram a força militar para a defesa de seus interesses nacionais, principalmente após o 11/09/2001.

Os ditos Estados falidos, frágeis e aqueles que abrigassem agentes das ditas "novas ameaças", principalmente terroristas, eram securitizados e sofriam sanções, que poderiam culminar em intervenções militares. Essa linha de pensamento remete ao pensamento huntingtoniano, de que os conflitos no Pós-Guerra Fria estariam 
ligados ao "choque de civilizações", em que o estabelecimento dos líderes dos Estados-Núcleo ${ }^{16}$ de cada civilização legitimaria os valores hegemônicos da civilização ocidental, trazendo a paz. Jaguaribe (2008) critica essa espécie de partilha do planeta, na qual os Estados-Núcleo tudo podem fazer em suas áreas de influência, em uma leitura que remete à ideia das Pan-regiões de Haushofer ${ }^{17}$. Ele mostra, ainda, que a "teoria de civilizações" era uma fixação da política externa estadunidense com a dita "civilização islâmica", sendo criada para legitimar os conflitos e intervenções no Oriente Médio e países afins.

Exemplos recentes mostraram que, para a manutenção de uma estrutura política, mormente imperial ou baseada na hegemônica coercitiva com sucesso, gastos excessivos devem ser utilizados para se exercer tal dominação. O governo Barack Obama (2009-17), de acordo com Lindsay (2011), seguiu uma estratégia mais smart. Sua disposição em "ouvir" e exercer o poder de forma mais multilateral o aproximou dos velhos aliados da Europa e da Ásia, diversificando a atuação na política externa.

A estratégia de Donald Trump (2017- ) parece mais ligada ao realismo ofensivo de Mearsheimer, ao tentar impedir, a todo custo, a chegada de um novo hegemon. Porém, Alisson (2017) não descarta outras teorias, como a de Waltz, que é mais flexível e menos tendente à guerra ou uma estratégia smart, que possibilitaria aos EUA exercer um papel de "balanceador" do novo sistema.

Quanto aos países em desenvolvimento e emergentes, Figueiredo (2015) critica a forma como é tratada a maturação de seus pensamentos estratégicos. Ele afirma que, para os Estados poderosos, a defesa ganha dimensão geográfica, podendo seus interesses estar sediados em outros territórios que não os seus próprios. O sentido de nacional alarga-se e pode estar situado no internacional. Para os Estados com menos poder, nada é mais ideal e menos nacional do que a sua própria defesa, em que os sistemas e planos de defesa são feitos somente para constar. Geralmente essas Nações assinam alianças com Estados mais fortes, subordinando sua segurança externa e defesa a esses outros, com suas forças armadas direcionadas mais a assuntos internos do que externos. Sobre tal assertiva,

${ }^{16} \mathrm{O}$ conceito de Estado-Núcleo se refere a uma nova categoria de poder. As civilizações são como famílias e os Estados-Núcleos representam o líder dos demais Estados daquele bloco, que o veem como provedor de apoio e disciplina (HUNTINGTON, 1997).

17 Teoria apresentada pelo geógrafo alemão Haushofer, que tinha como base a divisão do mundo em quatro regiões naturais: a Pan-América, Pan-Europa, Pan-Asia e Pan-Rússia. Na realidade, ele elaborou um modelo de "ordem mundial ideal", que consistia em uma aliança entre Alemanha, Rússia e Japão, sem alterar a área de influência dos EUA (TOSTA, 1984). 
pode-se dizer que, nas últimas décadas, a maioria dos países em desenvolvimento aplicou estratégias baseadas, quase que exclusivamente, em soft power. Essa estratégia é implementada quando o Estado não possui as condições financeiras adequadas, somadas a não participação mais efetiva de suas sociedades em assuntos de política externa e de defesa.

Sobre a criação de um sistema financeiro concorrente às instituições de Bretton Woods, o Banco Asiático de Investimento em Infraestrutura (AllB) é o primeiro banco de desenvolvimento de proporções extremamente significativas fora do eixo ocidental. Além do AllB, há o Banco de Desenvolvimento da China (CDB), o Banco de Desenvolvimento China-África (CADB), o Banco dos BRICS (criado na VI cúpula dos BRICS, em 15/07/2014, em Fortaleza, com capital inicial de US\$100 bilhões e sede em Xangai) e o Fundo da Rota da Seda. Com isso, propõe-se uma nova ordem financeira-econômica internacional de cunho revisionista, proporcionando novos espaços de cooperação econômica, após a crise financeira de 2008. De acordo com Vadell e Ramos (2005), esses bancos complementam os mecanismos de financiamento a projetos de infraestrutura no mundo em desenvolvimento, de forma mais particular na Ásia.

Já o projeto OBOR (One Belt, One Road ${ }^{18}$ ) configura-se em um ambicioso corredor de influência político, estratégico e econômico pela cooperação em todas as áreas, principalmente em infraestrutura, sendo capaz de integrar o Extremo Oriente à Europa Ocidental a partir da Rússia, por via terrestre, e a partir do Oceano Índico por via marítima.

No total, O OBOR busca integrar Ásia, África e Europa por cinco rotas diferentes. Em relação ao Cinturão Econômico continental, são três as rotas que conectam: a) China e Europa, através da Ásia Central e da Rússia; b) China e Oriente Médio, através da Ásia Central; e c) China, Sudeste Asiático, Ásia Meridional e Oceano Índico. Quanto à Rota da Seda Marítima, duas rotas a integram: d) China e Europa, através do Mar do Sul da China e Oceano Índico; e) China, Pacífico Sul e o Mar do Sul da China. Tal iniciativa aproveita a já existente infraestrutura logística internacional - assim como cidades centrais e portos importantes - de modo a estabelecer seis corredores econômicos internacionais: a) China-Mongólia-Rússia; b) New Eurasian Land Bridge; c) China-Ásia Central-Ásia Ocidental; d) BangladeshChina-Índia-Mianmar; e) China-Península Indochina; e f) China-Paquistão (PAUTASSO e UNGARETT, 2016). 
Esses corredores econômicos (Figuras 1 e 2) podem ter suas infraestruturas logísticas utilizadas em caso de conflito, como foi feito no cinturão de ilhas do Atlântico Sul, onde "Ascensão" teve papel preponderante para a logística das aeronaves e navios da força tarefa inglesa na Guerra das Malvinas (1982). O eventual êxito dessa proposta pode projetar a liderança da China e deslocar o domínio dos EUA nessas regiões, alterando, substantivamente, a configuração de poder mundial.

Figura 1 - Cinturão Econômico da Rota da Seda e Nova Rota da Seda Marítima

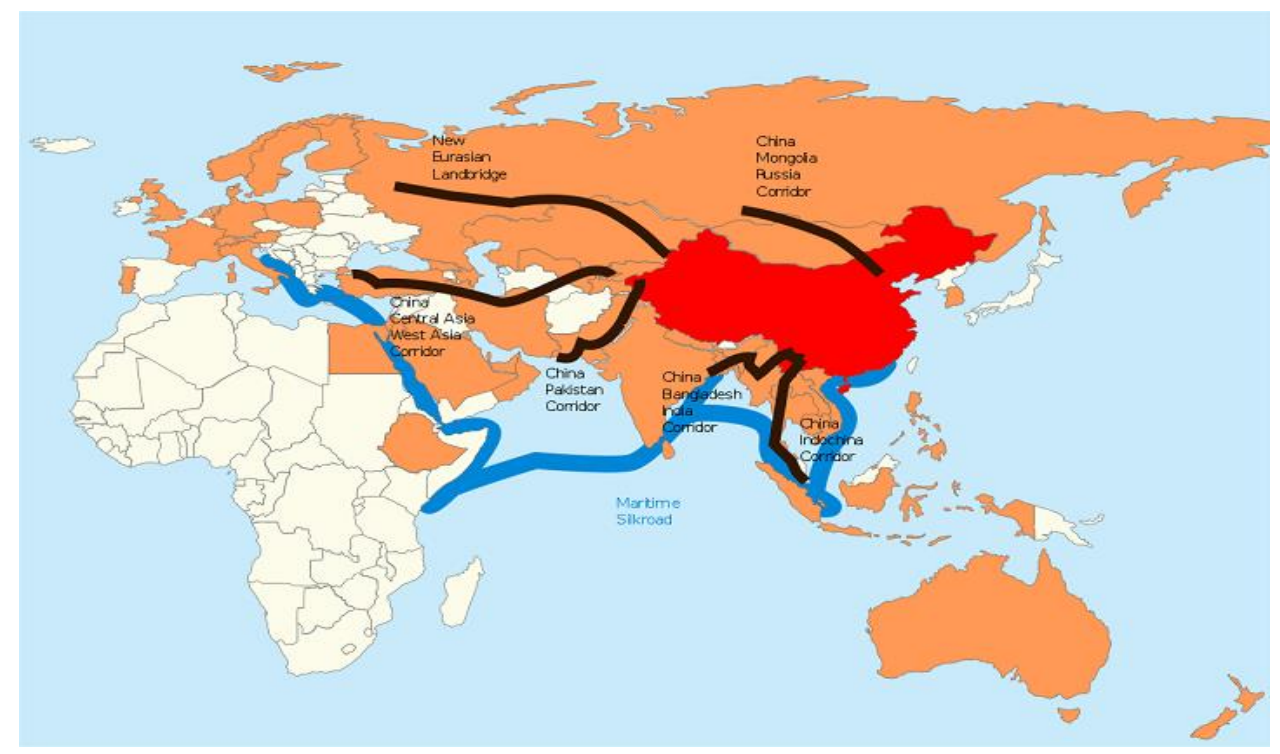

Fonte: Hong Kong Trade Development Council (2016)

Como contraponto a essa tentativa de um novo reequilíbrio de poder, os EUA lançaram, em 2018, um programa de cooperação denominado US BUILD ACT, visando à otimização de investimentos para o desenvolvimento, principalmente na Ásia e África. Tal ação busca defender sua posição global frente a uma ameaça potencialmente hegemônica. O BUILD $A C T^{19}$ obteve um forte apoio e uma rápida implementação por diversos setores governamentais e não-governamentais estadunidenses que, pela cooperação e dissuasão, visava manter seu status quo em pontos estratégicos dessas regiões.

Os EUA ainda têm acenado aos Estados em desenvolvimento com empréstimos, valendo-se do Fundo Monetário Internacional (FMI). Entretanto, há condições de ajustes estruturais para o governo dos Estados adquirentes. Já os 
empréstimos chineses, efetuados bilateralmente ou por meio de seus bancos de fomento, não possuem quaisquer requisitos políticos ou econômicos. A estratégia chinesa, de uso de poder econômico para aumentar sua influência em áreas estratégicas concorrentes com os EUA, também é uma resposta à negativa de instituições financeiras globais ocidentais, como o FMI, de permitir que a China aumente os direitos de voto no fundo (PAUTASSO e UNGARETTI, 2016).

Similarmente aos EUA, a visão chinesa de aplicação de soft power é de viés realista, compreendendo, segundo Morgenthau (1962), que "a cooperação é uma ação política, um instrumento de política externa de um Estado, a fim de ampliar seu poder, prestígio e ganhos econômicos no Sistema Internacional”. Todavia, a China não busca impor sua cultura e valores, como os EUA fazem, de forma bem assertiva, com os valores ocidentais em todo o mundo. A China quer que sua cultura e diferentes valores sejam respeitados. Sua política externa, segundo Allison (2017), aponta para uma visão hierarquizada do sitema internacional, não ligada a proselitismos e humanitarismos, haja vista a questão dos direitos humanos e do uso da força, caso necessário.

Figura 2 - Corredores Econômicos Internacionais

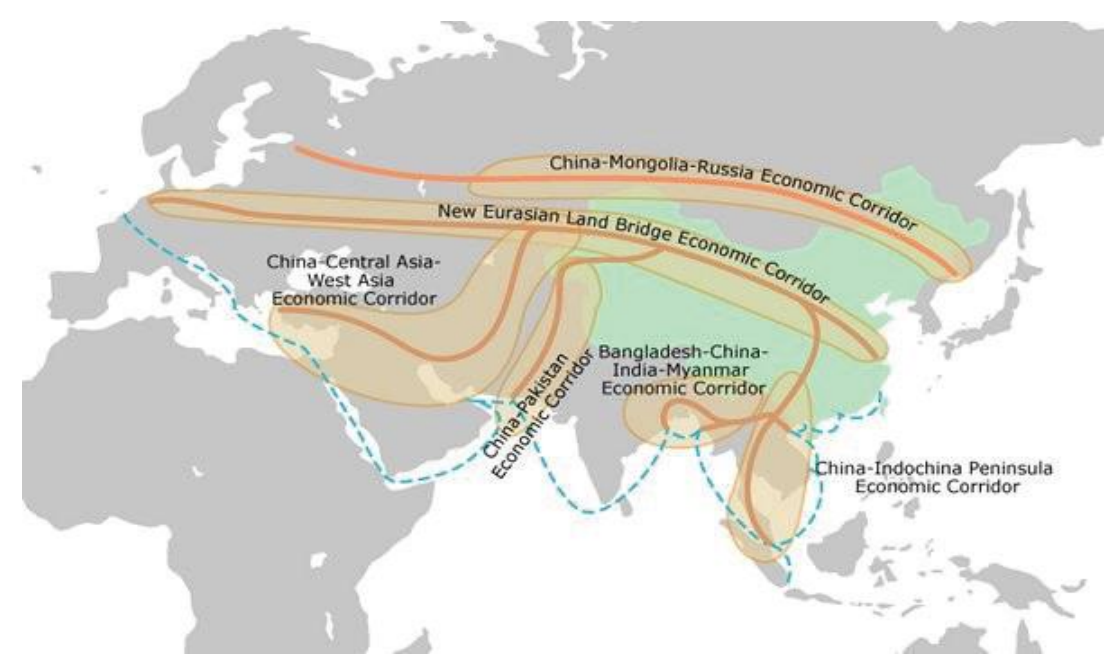

Fonte: Hong Kong Trade Development Council (2016)

Sobre seu hard power de viés militar, sua história, tradição e ações demostram pouca tendência ao belicismo ou expansionismos, desde a constituição de seu império na Antiguidade. Os chineses não abdicam do combate. Lutam quando são atacados ou fortemente ameaçados, o que remete a um pensamento do estrategista militar chinês Sun Tzu, de que a melhor batalha a ser travada é aquela em que não se precisa lutar (TZU, 2019). 
A História mostra que, até meados do século XIX, a China era uma força econômica e intelectual relevante, mas sucumbiu ante um poder militar mais tecnológico. Esse período ficou conhecido como o século das humilhações, que vai desde a $1^{\text {a }}$ Guerra do Ópio (1839-42) até o estabelecimento da República Popular da China, em 1949. Por isso, a estratégia naval chinesa visa estabelecer uma marinha oceânica, capaz de estabelecer influência em suas áreas de interesse primário, garantindo, primeiramente, a superioridade nos mares formados pela primeira cadeia de ilhas próximas ao seu território, o que envolve o Japão, Taiwan, as Filipinas e o sul do Mar da China para, posteriormente, ser capaz de projetar poder globalmente, em uma estratégia que não possui pressa para ser posta em prática. Assim, o forte investimento em defesa não foge de sua filosofia.

\section{Nova Guerra Fria? EUA versus China? Breves Discussões}

Os EUA e a China possuem economias fortemente interdependentes. Uma ameaça chinesa poderá desestabilizar sua economia, que depende muito de seu principal importador - os EUA. Paralelamente, os EUA dependem de uma relação afirmativa, pois a China é o maior financiador de sua dívida externa, sendo um dos maiores credores dos títulos do Tesouro Estadunidense. Esta forte ligação econômica acaba gerando uma estabilidade, também política, entre ambos os atores.

No entanto, de acordo com Allison (2017), os EUA e a China podem entrar em guerra por vários motivos: a) a crise em Taiwan pode escalar, resultando em um desembarque estadunidense em apoio às demandas taiwanesas; b) instabilidade na Coreia do Norte, causada por uma morte prematura de Kim Jong Um, pode causar nova luta por espaço e poder na península coreana, em uma guerra que ainda não acabou (não há um tratado de paz entre as duas Coreias), além de uma "corrida" de forças especiais dos EUA e China para o controle de seu armamento nuclear; c) um grande ataque cibernetico chinês poderá causar a desconfiança nos EUA de estarem sob ataque em sua esquadra no Pacífico; d) uma retaliação estadunidense no grande firewall chinês poderá ser visto como uma tentativa de derrubada de seu governo; e e) as disputas marítimas entre a China e países sob o guarda-chuva nuclear estadunidense poderá ocasionar um conflito no Mar do Sul da China.

Uma nova Guerra Hegemônica não pode ser desprezada entre EUA e China. Nos próximos anos ocorrerão várias "faíscas", que podem iniciar um conflito de proporções desconhecidas ou, ainda, uma perigosa dinâmica que ocorre quando 
uma potência emergente cria condições estruturais de estresse severos, provocando incidentes com terceiros, ou acidentes (questões objetivas) e intenções subjetivas, que seriam administráveis, podendo causar uma guerra de grandes proporções. Por serem potências nucleares, acredita-se, caso haja fortes acirramentos entre ambos, que seja mais provável a constituição de uma $2^{\text {a }}$ Guerra Fria, em conflitos limitados, localizados, indiretos e diretos, do que uma nova guerra total.

Como contraponto a uma possível nova Guerra Fria, Ferguson ${ }^{20}$ afirma que seria muito difícil replicá-la, porque os EUA e a China são muito interligados, enquanto que a ex-URSS era completamente separada. Para ele, qualquer escalada do conflito, além da guerra comercial e da guerra de informação, poderá ocorrer de forma direta e não em conflitos indiretos. Percebe-se, hoje, que a disputa maior é comercial, financeira e cibernética.

Nessa compreensão, há muitas outras hipóteses de conflito, mas talvez a que mais preocupe os EUA seja, justamente, a tecnológica. Por meio de investimentos em novas matrizes energéticas, equipamentos de alta tecnologia e de alto valor agregado, um Estado é capaz de alicerçar seu desenvolvimento com um parque tecnológico, capaz de colocá-lo como um diferencial no sistema internacional. A China poderá, brevemente, dominar tecnologias-chave para usos múltiplos, principalmente o espacial, o ciberespaço e a inteligência artificial. No caso da inteligência artificial, Ferguson ${ }^{21}$ acrescenta que, na computação quântica, há uma gama ampla de opções para ataques cibernéticos, desde pequenos até os que destruam a infraestrutura de um país. Essa é a principal luta por poder que está sendo travada na atualidade - a 4⿳亠丷a revolução industrial.

\section{Considerações Finais}

A Teoria do Poder Hegemônico, originada da narrativa da Guerra do Peloponeso, da obra de Tucídides, apresenta uma dinâmica perigosa que ocorre quando um poder em ascensão ameaça a posição de um poder já estabelecido. Na Grécia antiga, Atenas ameaçou Esparta. Ao final do século XIX e começo do século XX, a Alemanha desafiou o Reino Unido. Hoje, uma China em ascensão econômica e militar é um potencial desafiante à hegemonia estadunidense.

20 EUA e China estão à beira da guerra fria. Entrevista de Niall Ferguson. Valor Econômico. 05/12/2018. Disponível em: <https://www.valor.com.br/financas/6012959/eua-e-china-estao-beira-daguerra-fria-diz-niall-ferguson> Acesso em: 07 jul. 2019.

21 EUA e China estão à beira da guerra fria. Entrevista de Niall Ferguson. Valor Econômico. 05/12/2018. Disponível em: <https://www.valor.com.br/financas/6012959/eua-e-china-estao-beira-daguerra-fria-diz-niall-ferguson> Acesso em: 07 jul. 2019. 
O uso da força em prol dos objetivos políticos dos Estados, visando, primordialmente, sua sobrevivência e projeção de poder, continuará a ocorrer na dinâmica entre os Estados. Análises de que os EUA entregarão, pacificamente, o poder em áreas por eles antes dominadas fogem do contexto de sua História contemporânea - da sua luta pela independência, das guerras de expansões territoriais, da projeção de poder marítimo, da Doutrina Monroe, da política do Big Stick, etc. Outras análises de que a China busca uma hegemonia, custe o que custar, fogem de sua filosofia da guerra, tradições e história.

Por outro lado, há argumentos que ressaltam a ameaça e o perigo que a China representa para a segurança dos EUA. A explicação dada por Tucídides para o conflito entre Atenas e Esparta, em que o crescimento de Atenas e o medo provocado em Esparta foi o responsável pela guerra, contribui para ampliar o foco da análise para o comportamento dos EUA diante do crescimento chinês. A partir desta análise, é possível pensar em uma ameaça mútua, porém desigual, pois se a China é considerada uma ameaça hegemônica para os EUA, este representa uma ameaça à manutenção do crescimento econômico chinês na solidificação do caminho de seu desenvolvimento econômico e em uma trajetória de maior assertividade e inserção sistêmica.

Embora a China esteja buscando construir a maior marinha do mundo, sua ascensão econômica, mesmo que notável, não lhe dá condições para contrapor-se militarmente aos EUA na atualidade e no curto prazo. A China poderá equiparar-se aos EUA ou, pelo menos, elevar os custos de uma intervenção em seu entorno estratégico imediato, que abarca a região leste da Ásia e os mares adjacentes ao seu território, cujo argumento é embasado na segurança e defesa, uma vez que a região é fundamental na manutenção de sua economia e soberania.

A forte interdependência econômica entre os dois Estados é um fator preponderante para se evitar grandes conflitos, além da distensão nuclear. Entretanto, não se pode desprezar uma nova Guerra Hegemônica, pois, relembrando Tucidides, fatores subjacentes e inesperados poderão ocorrer e propiciar um conflito de grandes proporções. Para isso, basta que as paixões vençam a racionalidade e os freios e contrapesos de seus sistemas políticos não funcionem (democracia liberal e centralização autocrática). Há possibilidade, ainda, da ocorrência de conflitos indiretos, como em uma 2a Guerra Fria. Todas essas possibilidades são embasadas em análises de perspectivas dentro do contexto 
histórico, filosófico, de suas capacidades de poder real e potencial e, principalmente, das atuais conjunturas interna e externa.

A armadilha de Tucídides está montada. As estratégias de manutenção (EUA) e de revisão (China) do status quo estão colocadas no tabuleiro geopolítico. A luta por uma readequação do sistema internacional poderá resultar em uma nova hegemonia, na manutenção da atual ou, ainda, em um novo equilíbrio de poder em áreas de influência, o que possibilitaria atender aos EUA e à China, além de outros atores relevantes, como a Rússia e a Índia, desde que seus interesses se coadunem.

\section{REFERÊNCIAS}

ALLISON, Graham. Destined for War: Can America and China Escape Thucydides's Trap? New York: Houghton Mifflin Harcourt, 2017.

Bardin, L. Análise de Conteúdo. São Paulo: Edições 70, 2011.

BELLIGNI, Silvano. Hegemonia. Dicionário de Política. In: BOBBIO, Norberto, MATTEUCCI, Nicola e PASQUINO, Gianfranco. trad. Carmem C, Varriale et al.; coord. Trad. João Ferreira; rev. Geral João Ferreira e Luis Guerreiro Pinto Cacais. 13ed. Brasília: Editora Universidade de Brasília, 2008.

BODIN, Jean. On Sovereignty. New York: Cambridge University Press, 1992.

CARR, Edward Hallett. Vinte Anos de Crise:1919-1939. Brasília: Universidade de Brasília, 1981.

EUA E CHINA ESTÃO À BEIRA DA GUERRA FRIA. Entrevista de Niall Ferguson. Valor Econômico. 05/12/2018. Disponível em: <https://www.valor.com.br/financas/6012959/euae-china-estao-beira-da-guerra-fria-diz-niall-ferguson> Acesso em: 07 jul. 2019.

FIGUEIREDO, Eurico de Lima. Pensamento Estratégico Brasileiro- Discursos. Rio de Janeiro: Editora Luzes - Comunicação, Arte \& Cultura. 2015.

GILPIN, Robert. War and change in world politics. Cambridge: Cambridge University Press, 1981.

GILPIN, Robert. The Theory of War Hegemonic Source: The Journal of Interdisciplinary History, Vol. 18, №. 4, 1988. The Origin and Prevention of Major Wars (Spring, 1988), pp. 591-613 Published by: The MIT Press Stable. Disponível em: <http://www.jstor.org/stable/204816>, Acesso em: 15 dez. 2019.

GRAMSCI, Antonio. Cadernos do Cárcere. v.2. São Paulo: Editora Civilização Brasileira, 2000.

HASENCLEVER, A.; MAYER, P. e RITTBERGER, V. Theories of International Regimes. Cambridge: Cambridge University Press, 1997. 
HERZ, Mônica e HOFFMANN, Andrea Ribeiro. Organizações Internacionais: história e práticas. Rio de Janeiro: Elsevier, 2004.

HONG KONG TRADE DEVELOPMENT COUNCIL (2016). Disponível em:

$<$ https://www.hktdc.com/> Acesso em: 04 jul.2019.

HRUBY, Abrey. With new development finance agency, the US matches China's ante, Axios (Oct. 18, 2018). Disponível em: <https://www.axios.com/with-new-developmentfinance-agency-the-us-matches-chinas-ante-0cd20aad-9571-4e16-91b183e632b1c2c2.htm>. Acesso em: 02 jul. 2019.

HUNTINGTON, Samuel P. The Clash of Civilizations and the Remaking of World Order. New York; London: Simon and Schuster, 2007.

JAGUARIBE, Hélio. Brasil, mundo e homem na atualidade: estudos diversos. Brasília: Fundação Alexandre Gusmão, 2008.

KENNEDY, Paul. Ascensão e Queda das Grandes Potências: transformação econômica e conflito militar de 1500 a 2000. Rio de Janeiro: Campus, 1989.

KEOHANE, Robert O. After Hegemony: discord and cooperation in the world political economy. Princeton, NJ: Princeton University Press, 1984.

LESSA, Antônio Carlos. História das Relações Internacionais: a Pax Britannica e o mundo do Século XIX. Petrópolis, RJ: Vozes, 2005.

LINDSAY, James M. George W. Bush, Barack Obama and the future of US global leadership. International Affairs, v.87, n.4, p.65-779, 2011.

LUDWIG, Fernando José. A hegemonia enquanto formação da arquitetura de paz das Nações Unidas. Relações Internacionais (R: I), n. 39, p. 69-77, 2013.

MAGENDZO, Abraham. Pensamiento e ideas-fuerza em la educación em derechos humanos em Iberoamerica. CREALC-UNESCO, 2009.

MANTTEUCCI, Nicola. Hegemonia. Dicionário de Política. In: BOBBIO, Norberto, MATTEUCCI, Nicola e PASQUINO, Gianfranco. trad. Carmem C, Varriale et al.; coord. Trad. João Ferreira; rev. Geral João Ferreira e Luis Guerreiro Pinto Cacais. 13.ed. Brasília: Editora Universidade de Brasília, 2008.

MEARSHEIMER, John J. A Tragédia das Políticas das Grandes Potências. Tradução de Thiago Araújo. Lisboa: Gradiva, 2007.

MORGENTHAU, H. A Political Theory of Foreign Aid. The American Political Science Review, v.LVI, n.2, p.301-309, 1962.

NYE, Joseph S. O Futuro do Poder. Tradução de Magna Lopes. São Paulo: Benvirá, 2012.

PAUTASSO, Diego; UNGARETTI, Carlos Renato. A Nova Rota da Seda e a recriação do sistema sinocêntrico. Estudos Internacionais: Revista de Relações Internacionais da PUC Minas, v. 4, n. 3, p. 25-44, 2016.

PAUTASSO, Diego. China e Rússia e a integração asiática: O sistema sinocêntrico como parte da transição sistêmica. Revista Conjuntura Austral, v.2, n.5. Porto Alegre. 2011. Disponível em: <http://oaji.net/articles/2015/2137-1437661747.pdf> Disponível em: 07 jul.2019. 
PAUTASSO, Diego. A China na nova arquitetura geoeconômica global e o caso do Banco Asiático de Investimento em Infraestrutura. In: Meridiano 47. v. 16, 2015, p. 12-19.

PISTONE, Sergio. Imperialismo. Dicionário de Política. In: BOBBIO, Norberto, MATTEUCCI, Nicola e PASQUINO, Gianfranco. trad. Carmem C, Varriale et al.; coord. Trad. João Ferreira; rev. Geral João Ferreira e Luis Guerreiro Pinto Cacais. 13.ed. Brasília: Editora Universidade de Brasília, 2008.

RIGGS, Robert E.; PLANO, Jack C. The United Nations.International Organization and World Politics. Belmont, California: Wadsworth Publishing Company, Second Edition, 1994.

SILVA, Marco Antonio de Meneses. Teoria Crítica em Relações Internacionais. Contexto Internacional. v.27. n.2. Rio de Janeiro July/Dec. 2005. Disponível em: <http://www.scielo.br/scielo.php?script=sci_arttext\&pid=S0102-85292005000200001 >. Acesso em: 13 mar.2019.

STRAUSS, Barry. A Batalha de Salamina. Rio de Janeiro: Record, 2007.

SWAINE, Michael D. Chinese Views and Commentary on the "One Belt, One Road" Initiative. China Leadership Monitor, n. 47. 2015. Disponível em:

<https://www.hoover.org/sites/default/files/research/docs/clm47ms.pdf>. Acesso: 9 de abril de 2020.

TOSTA, Octavio. Teorias Geopolíticas. Rio de Janeiro: Biblioteca do Exército, 1984.

TUCÍDIDES. História da Guerra do Peloponeso; Prefácio de Helio JAGUARIBE; Trad. do grego de Mário da Gama Kury. - 4.ed. Brasília: Editora Universidade de Brasília, Instituto de Pesquisa de Relações Internacionais; São Paulo: Imprensa Oficial do Estado de São Paulo, 2001 XLVII, 584 p., 23 em Clássicos IPRI, 2.

TZU, Sun. A arte da guerra. São Paulo: Penguin-Companhia das Letras, 2019.

VADELL, Javier; RAMOS, Leonardo. As Sedutoras Garras do Dragão Chinês: Finanças e Bifurcação do Centro da Economia Global, Grupo de Pesquisa sobre Potências Médias, Belo Horizonte, 2015.

WALTZ, Kenneth. Teoria das Relações Internacionais. Lisboa: Gradiva, 2002.

WEBER, Max. A Política como Vocação. In: WEBER, Max. Ciência e Política, Duas Vocações. São Paulo: Editora Cultrix, 1996. p. 53-124.

\section{NOTAS DE AUTOR}

\section{CONTRIBUIÇÃO DE AUTORIA}

Alexandre Rocha Violante - Concepção. Coleta e análise de dados, elaboração do manuscrito, revisão e aprovação da versão final do trabalho.

Etiene Villela Marroni - Participação ativa da discussão dos resultados; Revisão e aprovação da versão final do trabalho.

André Valente Maia - Participação ativa da discussão dos resultados; Revisão e aprovação da versão final do trabalho.

FINANCIAMENTO

Não se aplica. 
APROVAÇÃO DE COMITÊ DE ÉTICA EM PESQUISA

Não se aplica.

CONFLITO DE INTERESSES

Não se aplica.

\section{LICENÇA DE USO}

Este artigo está licenciado sob a Licença Creative Commons CC-BY. Com essa licença você pode compartilhar, adaptar, criar para qualquer fim, desde que atribua a autoria da obra.

\section{HISTÓRICO}

Recebido em:15-05-2020

Aprovado em: 02-08-2020 